\title{
Comparison of Antimicrobial and Wound Healing Agents on Oral Fibroblast Viability and In-vivo Bacterial Load
}

\section{Bowen $\mathrm{J}^{1 *}$, Cole $\mathrm{C}^{2}$ and McGlennen $\mathrm{R}^{3}$}

${ }^{1}$ Dental Arts, Independence, MO, USA

${ }^{2}$ Likarda LLC, Kansas City, KS, USA

${ }^{3}$ Oral DNA, Eden Prairie, MN, USA

\begin{abstract}
Oral rinses are designed to restore healing (often for mouth sores) or kill oral bacteria. The balance between bactericidal and restorative effects is not often achieved, leading to unwanted side effects of the products. In this study we ran comparisons of currently available cleansing rinses, measuring possible toxic effects on gingival fibroblasts invitro and their bactericidal effects in-vivo. The commercial products tested included oral rinses based on: chlorhexidine gluconate, carbamide peroxide, aloe vera, essential oils (with and without alcohol) and a combination product with essential oils and carbamide peroxide. All products except the combination rinse caused $100 \%$ gingival fibroblast cell (HGF-1) death after a single 30 second rinse. In addition, the same products increased the cytotoxic effects of a chemotherapeutic even at its lowest dose. In a pilot human trial, an antimicrobial product (CHX) and the combination product were tested for effectiveness in reducing the bacterial load. Oral bacterial load was measured from sputum samples before and after a single rinse. Control samples were collected before and after a water rinse. Using PCR, bacterial DNA probes designed for 11 different gram-negative bacterium were tested. The combination product had the most reduction in total bacterial load, with statistically significant reduction in Aactinomycetem comitans, $T$ forsythia, $F$ nucleatum, $P$ intermedia, $P$ micros, and $C$ species. The results suggest that antimicrobial rinses can also be harmful to gingival fibroblasts, while only one restorative rinse was not toxic to gingival fibroblasts and still showed antimicrobial effects.
\end{abstract}

Keywords: Oral bacteria; Fibroblasts; Bacterial DNA; Human; Chlorhexidine gluconate; Carbamide peroxide; Essential oils

\section{Introduction}

The human mouth provides an optimal environment for bacterial growth. In fact more than 700 bacterial species have been identified in the oral cavity [1]. The oral bacterial flora plays an important role in normal periodontal health and overall human health [2]. When in symbiosis, the microbes are essential to human function, such as facilitating digestion of certain plant polysaccharides [3]. Alternatively, when the normal flora of the mouth is not in equity, the microbes found in the mouth can play a key role in the etiology of oral and systemic diseases [4]. In fact, periodontitis is one of the most common bacterial infections in humans with an estimated $47 \%$ of all US adults affected at any given time [5]. Periodontitis results in the production of orally-produced pro-inflammatory cytokines that enter the circulation and induce a systemic inflammatory condition that can be measured by serum levels of C-reactive protein [6,7]. The consequences of the long-standing oral inflammation have been linked to cancer [8-11], rheumatoid arthritis [12], chronic kidney disease [13], vascular disease $[14,15]$, dementia [16] and a host of other diseases [17,18].

It is well established that gram-negative bacteria are more commonly found in areas of the mouth with established periodontal disease, while healthy locations in the mouth contain predominantly gram-positive bacteria [19]. If not treated aggressively, the pathogens can destroy the supporting structures of the teeth, leading to a permanent loss of teeth. While the total bacterial load is important, the exact types of bacteria that invade the mouth are equally important when determining the disease process and prognosis [19]. In the 1990s, four major species of gram-negative bacteria were implicated in individuals with periodontal disease: $P$. gingivalis, A. actinomycetemcomitans, T. forsynthesis, and T. denticola [19]. These 4 bacteria are classified as high-risk for periodontal disease and other systemic diseases. In addition to the high-risk bacteria, other gram-negative bacterial species are classified as moderate- and low-risk.
With links to so many serious diseases, the importance of controlling oral bacteria is clear. The dental intervention for periodontal disease typically includes mechanical removal of the plaque biofilm and/ or surgical procedures in advanced cases. Scaling and root planning are currently the gold standard of non-surgical care for chronic periodontitis. In addition, the application of antimicrobials has been shown to be effective in improving probe depth measurements, and clinical attachment levels compared to mechanical cleaning alone [20]. Chlorhexidine (CHX) is commonly used as a major component in mouth rinses to reduce gingival infections. At high concentrations, it acts by damaging the bacterial cell wall, leading to bacterial death [21]. While there are studies indicating beneficial reductions of oral bacterial in response to $\mathrm{CHX}$ treatment [22], there are reports that rinsing with CHX has little or no long-term impact on oral health $[20,23]$.

Other antimicrobial rinses include carbamide peroxide, which at high enough concentrations elevates the mouth $\mathrm{pH}$ to levels that are harmful to bacteria [24]. However, it can also cause a reduction in hardness of some of the tooth enamel areas, and is best known as a teeth-whitening treatment rather than as an antimicrobial agent [25]. Other commercially-available antimicrobial oral rinses are based on essential oils like eucalyptol, menthol, and thymol. Like studies on the other oral rinses, the results of studies on the antibacterial effects of essential oil products have also been mixed [26-28].

*Corresponding author: Jeremy Bowen, DD, Dental Arts, 19201 East Valley View Parkway, Independence, MO 64055, Missouri, USA, Tel: 816478 3600; E-mail: jlbcmb03@sbcglobal.net; Ibittel@likarda.com

Received April 03, 2015; Accepted May 11, 2015; Published May 14, 2015

Citation: Bowen DJ, Cole C, McGlennen R (2015) Comparison of Antimicrobial and Wound Healing Agents on Oral Fibroblast Viability and In-vivo Bacterial Load. Dentistry 5: 305. doi:10.4172/2161-1122.1000305

Copyright: ( 2015 Bowen DJ, et al. This is an open-access article distributed under the terms of the Creative Commons Attribution License, which permits unrestricted use, distribution, and reproduction in any medium, provided the original author and source are credited. 
Unfortunately, many of the home-use antimicrobial rinses can cause unwanted death of the healthy oral cells at the commerciallyavailable concentrations [29]. The cell death occurs due to damage to DNA and proteins [11], which can result not only in oral mucositis, but it also decreases the body's natural defense against further bacterial invasion [30]. For this reason a joint endeavor by the International Society of Oral Oncology and Multinational Association of Supportive Care in Cancer issued a review of management of oral health and concluded that antimicrobials such as CHX should not be prescribed for cancer patients with mouth sores [31,32]. The group also reviewed research on a second category of rinses aimed at protecting the gingival cells and promoting wound healing, and again concluded that there were no strong research results to support their use with radiation or chemotherapy-induced oral mucositis [32,33].

New research is needed to identify products that have both a bactericidal effect, but are not toxic to the healthy oral cells [19]. In addition, there is a significant lack of side-by-side comparisons of currently marketed products for oral health. The purpose of this study was to examine the effect of several currently available rinses on gingival fibroblast viability. The tested agents included antimicrobial products (CHX, carbamide peroxide, and antimicrobial essential oils) compared to a wound healing product (Aloe Vera-based product), and a combination product with wound healing essential oils and carbamide peroxide. Subsequently, products from the antimicrobial and wound healing categories were tested for oral bacterial inhibition in human subjects.

\section{Methods}

\section{Cell culture}

Human gingival fibroblasts (HGF-1, purchased from ATCC) were grown in Dulbecco's Modified Eagle Medium (DMEM) and supplemented with $10 \%$ fetal bovine serum and $1 \%$ penicillin/ streptomycin. Cells were incubated at $37^{\circ} \mathrm{C}$ in $5.0 \% \mathrm{CO}_{2}$, with media changes approximately every 48 hours until they reached $80-90 \%$ confluence. Cells from passages 3-5 were seeded into 96-well plates for testing.

\section{In-vitro testing}

Cells were exposed to the oral rinses from different categories listed in Table 1. The commercially-available products chosen for each of the tested categories were Listerine (essential oils), CVS Aseptic Cleanser (carbamide peroxide), Denti-Rinse 3 (chlorhexidine gluconate), Rincinol (aloe vera), Triology (combination essential oils and carbamide peroxide) (Table 1). Products were tested at full strength (or at dilutions of 1:2 or 1:10) for 30 seconds, rinsed 3 times with media, with a final return to DMEM media. Each trial was conducted in 4-6 well replicates. Control wells underwent a vigorous media change for 30 seconds, but were not exposed to any product. 48 hours after the 30-second exposure, the cell numbers were measured using 2 independent assays. The 2 day post-treatment resting period was important to verify that counted cells were live. The microplate assays and the image-based cell counting software do not readily differentiate between live and dead cells. Culturing the cells for 2 days post-treatment ensured that only live cells were included in the cell count. Images were digitally captured from each well, and images analyzed with automated cell counting using a Celigo adherent cell cytometer (Cyntellect, Inc).

To verify the image-based cell counts, a fluorophore-based (resazurin) assay - PrestoBlue (Thermo Fisher Scientific) was utilized following manufacturer's guidelines. Fluorescence was read on a microplate reader (Enspire Multimode, PerkinElmer) 2-3 hours later. Results were averaged following background subtraction. Additional lethality curves were generated by sequential dilutions of the test products. Gingival fibroblasts were exposed to increasing doses of each product starting with a dilution of 1:2000. Experiments that evaluated the effect of pretreatment with the test product on doxorubicin-induced fibroblast cell death were completed by exposing gingival fibroblasts to a $30 \mathrm{sec}$ exposure of test products followed by 2 rinses and 96 hours incubation. Doxorubicin was added to wells at doses from $0.002-50$ $\mu \mathrm{M}$ for 24 hours. Viable cells were measured using the PrestoBlue assay described above. All experiments were completed in quadruplicate.

\section{Pilot Clinical Trial}

A single rinse pilot study was undertaken with 19 subjects to measure possible changes in oral bacteria from dental patients before and after a single rinse. The subjects ranged in age from $28-67$ with a mean age of $45.6 \pm 2.8$ years. Each subject consented to participation and had at least 20 erupted natural teeth, including at least 1 molar and 1 premolar in each quadrant. Subjects had no systemic or chronic disease, nor used removable partial dentures. None had been treated with antibiotics in the 3 months prior to the study. None of the participants were active smokers, and all reported brushing their teeth at least once/day. There were 5 subjects/group in the water and $\mathrm{CHX}$ treatment arms, and 9 subjects in the combination treatment group.

Sputum samples were collected from each participant as baseline bacterial loads. The samples were collected per the kit instructions, and tested with MYPERIPATH test (OralDNA Labs). Specifically, subjects were asked to rinse with saline solution provided by the kit manufacturer, then expectorate into a collection vial. Genomic DNA for 11 different bacteria was quantified using polymerase chain reaction (PCR) followed by fluorescent endpoint detection [34]. The 11 bacteria were classified according to their risk of periodontal disease as low-, moderate- or high-risk, summarized in Table 2.

\section{Statistics}

Paired t-tests were used for the human studies comparing bacterial levels before and after use. Fibroblast viability studies were analyzed

\begin{tabular}{|l|l|l|l|}
\hline Action & Category & Active ingredient(s) \\
\hline \multirow{2}{*}{ Antimicrobial } & Essential Oils (EO) & eucalyptol, menthol, methyl salicylate, thymol \\
\hline & Carbamide Peroxide (CP) & carbamide peroxide \\
\hline & Chlorhexidine gluconate (CHX) & chlorhexidine gluconate \\
\hline Wound healing & Aloe vera (AV) & $\begin{array}{l}\text { sodium hyaluronate, polyvinylpyrroliodone, } \\
\text { glycyrrhetinic acid, aloe vera extract, propylene glycol, } \\
\text { maltodextrin, potassium sorbate, sodium benzoate, } \\
\text { gydroxyethylcellulose, and other components }\end{array}$ \\
\hline Antimicrobial and healing & Rincinol \\
\hline & Combination (Combo) & $\begin{array}{l}\text { xylitol anhydrous, glycerin, carbamide peroxide, prunus } \\
\text { dulcis, triticum aestivum, aloe barbadensis, menthe } \\
\text { piperita oil, rosmarius officinalis oil, xantham gum }\end{array}$ \\
\hline
\end{tabular}

Table 1: List of oral rinses from different categories. 


\begin{tabular}{|l|l|l|}
\hline Classification & Bacteria & Abbreviation \\
\hline \multirow{4}{*}{ High-Risk } & Aggregatibacter actinomycetemcomitans & $\mathrm{Aa}$ \\
\hline & Porphyromonas gingivalis & $\mathrm{Pg}$ \\
\hline & Tannerella forsythia & $\mathrm{Tf}$ \\
\hline & Treponema denticola & $\mathrm{Td}$ \\
\hline \multirow{3}{*}{ Moderate-Risk } & Eubacterium nodatum & $\mathrm{En}$ \\
\hline & Fusobacterium nucleatum/periodonticum & $\mathrm{Fn}$ \\
\hline & Prevotella intermedia & $\mathrm{Pi}$ \\
\hline & Campylobacter rectus & $\mathrm{Cr}$ \\
\hline & Peptosterptococcus micros & $\mathrm{Pm}$ \\
\hline & Eikenella corrodens & $\mathrm{Ec}$ \\
\hline Low-Risk & Capnocytophaga species & $\mathrm{Cs}$ \\
\hline
\end{tabular}

Table 2: Classification of bacteria based on the risk of periodontal disease.

with ANOVA. LC50 calculations used standard curve analysis using a 4-point logistics function.

\section{Results}

\section{Comparison of cleanser effects on gingival fibroblasts}

The effect of oral cleansing agents on gingival fibroblast health was investigated by exposing fibroblasts to various commercially-available agents for 30 seconds. The 30 -second exposure was used to mimic the standard oral hygiene procedure of rinsing with each product. Figure 1 shows representative images from the automated cell counts that were conducted prior to exposure to the test product and after. Few cells exposed to chlorhexidine gluconate survived the treatment, as can be seen in Figure 1. Those few remaining cells had lost their elongated shape and were rounded (see black arrow). Exposure to carbamide peroxide left cellular debri in the plates. Essential oils caused a reduction in cell number, but there were still some viable cells left after the 30 minute exposure to the essential oil, and they maintained their natural elongated shape (see white arrow). The combination product of essential oils and carbamide peroxide resulted in large numbers of viable cells. The aleo vera treatment left some viable cells behind in both the rounded shape (black arrow) or elongated (white arrow).

The results are summarized in Figure 2. Media change alone caused a $4 \%$ decline in viable cell number. In contrast, the antimicrobial agents caused a dramatic decline in live cell numbers. CHX exposure resulted in a $94 \%$ reduction in cell number. Carbamide peroxide (CP) resulted in a $95 \%$ decline in cell number. The essential oil (EO) product caused a $93 \%$ decrease in live cells and removal of alcohol from that product did not alter the results. Surprisingly, the wound-healing product based on aloe vera (AV) also caused significant cell death. Of the products tested, only the combination EO + CP product (Combo) maintained significant cell numbers with only an $18 \%$ decline in viable cells. Reduction in the concentration of each test product by diluting in media at a 1:10 ratio did not alter the results (results not shown).

The results from automated cell count from digital images were verified using a microplate reader assay with a live-cell fluorophore. Again, viable cells were only maintained after exposure to the control media and the combination rinse. The results are summarized in Table 3 . The $\%$ decline in the combination treatment was greater in the fluorescence assay. This may have been because the fluorophore used only detected live cells, while the digital imaging procedure counts all cells still attached in the wells. Still the trend was the same for both independent cell viability assays.
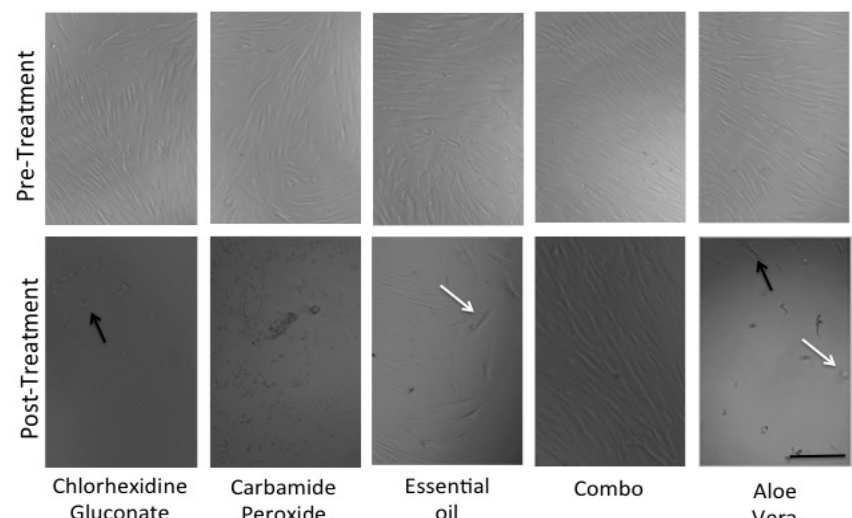

Essential

oil
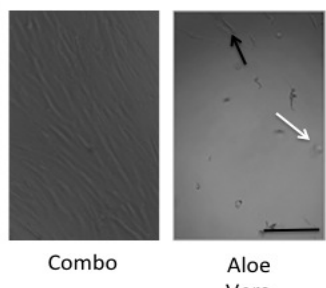

Gluconat

Peroxide

Combo

Vera

Figure 1: Effect of rinse agents on the viability of oral fibroblasts.Cells were plated into 96 well plates and images captured prior to treatment (upper panels). After treatment, images were captured for the same wells, and automated cell counts conducted. The images illustrate the typical results when cells were exposed to the rinse containing chlorhexidine gluconate, carbamide peroxide, essential oil product, and a combination product. Black arrows indicate examples of rounded cell structure. White arrows indicated elongated cells. Scale bar $=100 \mu \mathrm{m}$.

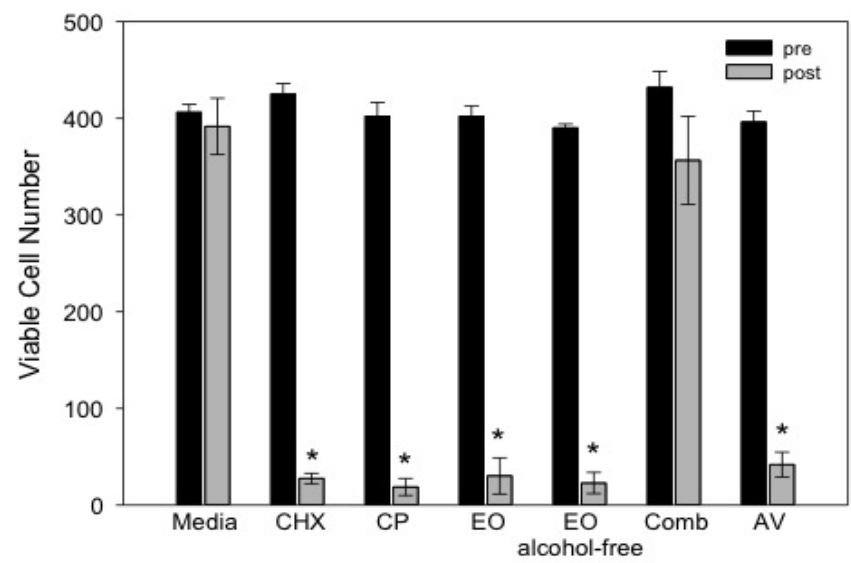

Figure 2: Summary of all cell viability tests rinse products. The cell number/ visual field was counted using an automated digital process. The pretreatment values are shown in black with post-treatment in gray. A media change cause no significant decline in cell number, but treatment with $\mathrm{CHX}$, carbamide peroxide (CP), essential oil-based rinse (EO) with and withou alcohol, and an aloe vera-based product (AV) all caused a significant drop in cell numbers. Only the combination treatment did not statistically reduce the cell number. *indicates $\mathrm{p}<0.05$. CHX: chlorhexidine gluconate, $\mathrm{CP}$. carbamide peroxide, EO: essential oils, and essential oils alcohol-free, comb: combination product, $\mathrm{AV}$ : aloe vera.

\section{Fibroblast dose/response}

A 30 second exposure to most of the test products at full strength or a 1:10 dilution resulted in complete cell death. In order to conduct viability assays, sequential dilutions were made totest cell viability using the live cell fluorophore assay. Gingival fibroblasts were exposed to increasing doses of each product starting with a dilution of 1:2000. Table 4 summarizes the effect of the 3 least toxic products to fibroblast viability. The LD50 for the combination product was statistically greater than the essential oils, indicating that it was less toxic. In fact the combination product was significantly less toxic to fibroblasts compared to all other products at both $25 \%$ and $50 \%$ dilutions $(\mathrm{P}<$ $0.002)$. 


\begin{tabular}{|c|c|c|}
\hline Treatment & $\begin{array}{c}\text { Cell Number (relative fluorescence } \\
\text { value) }\end{array}$ & \% decline \\
\hline Media change & $9624.91 \pm 263.97$ & - \\
\hline Essential oils & $1.91 \pm 5.7$ & 100 \\
\hline Essential oils (alcohol free) & $0.412 \pm 7.26$ & 100 \\
\hline Carbamide peroxide & $3.38 \pm 2.53$ & 100 \\
\hline Chlorhexidine gluconate & $6.25 \pm 2.31$ & 100 \\
\hline Combination & $2750.41 \pm 382.01$ & 71 \\
\hline Aloe Vera & $3.59 \pm 17.41$ & 100 \\
\hline
\end{tabular}

Table 3: Viable cells exposure to the control media and the combination rinse.

\begin{tabular}{|c|c|c|}
\hline Treatment & IC50 (\% full strength) & Hill Slope \\
\hline Essential oils & $25.59 \pm 2.54$ & $-5.07 \pm 4.7$ \\
\hline Combination & $38.31 \pm 7.85$ & $-2.67 \pm 1.06$ \\
\hline Aloe Vera & $26.62 \pm 5.69$ & $-2.54 \pm 1.16$ \\
\hline
\end{tabular}

Table 4: Effect of the 3 least toxic products to fibroblast viability.

The previous study was conducted on healthy gingival fibroblasts. Often such products are prescribed for patients who have existing challenges to oral health through disease states or administration of certain drugs. To mimic that situation, fibroblasts were exposed to doxorubicin, a common chemotherapy known to cause mucositis [29]. Gingival fibroblasts were exposed to the 3 least toxic test products (EO, Combo, and AV) for $1 \mathrm{~min}$ at a 1:2 dilution. They were subsequently exposed to a single sequential dose of doxorubicin (6 log dose range) for 24 hours. The results are shown in Figure 3. Even at the lowest dose of doxorubicin, EO and AV caused further cell death beyond doxorubicin alone. At the lowest doxorubicin doses, the Combo treatment did increase cell death, but not to the level of the other 2 products.

\section{In-vivo bactericidal effects}

A single rinse pilot study was undertaken with 19 subjects to determine whether a single rinse with the combo product, the CHX-based product or a control water rinse reduced bacterial load statistically. Figure 4A shows the results of the water rinse. No bacterial category had a significant change in bacterial load after a water rinse. With CHX, there was a trend towards reduction in some of the bacteria subtypes including Tannerella forsythia (Tf,) Fusobacterium nucleatum/periodonticum (Fn), and Prevotella intermedia (Pi), but only Peptostreptococcus micros (Pm) was statistically reduced (Figure $4 \mathrm{~B})$. Comb treatment resulted in the greatest bacterial load reduction, which occurred in the high-, moderate- and low-risk categories of bacteria (Figure 4C). Aactinomycetem comitans, T. forsythia, F. nucleatum, $P$. intermedia, $C$. rectus, $P$. micros, and $C$. species all showed statistically significant reductions in bacteria.

\section{Discussion}

The human mouth is an active biome with beneficial bacteria, as well as bacteria that cause dental decay and eventually systemic disease [19]. Unlike some other parts of the body, the oral microbiome is extremely dynamic, because new microbes are being introduced daily, based on what the person puts in their mouth [35]. Many over-thecounter and prescription rinses have been developed, allowing the patient to treat oral infections at home. However, research supporting the antimicrobial effects of some of these products have been mixed, and there are concerns that these same products are harmful to oral cells. The purpose of this study was to compare the effects of marketed oral antimicrobial and wound healing rinses for their bactericidal effect and possible lethality to fibroblasts.

The bacteria tested in this study have been shown to be some of the most common microorganisms associated with periodontal disease

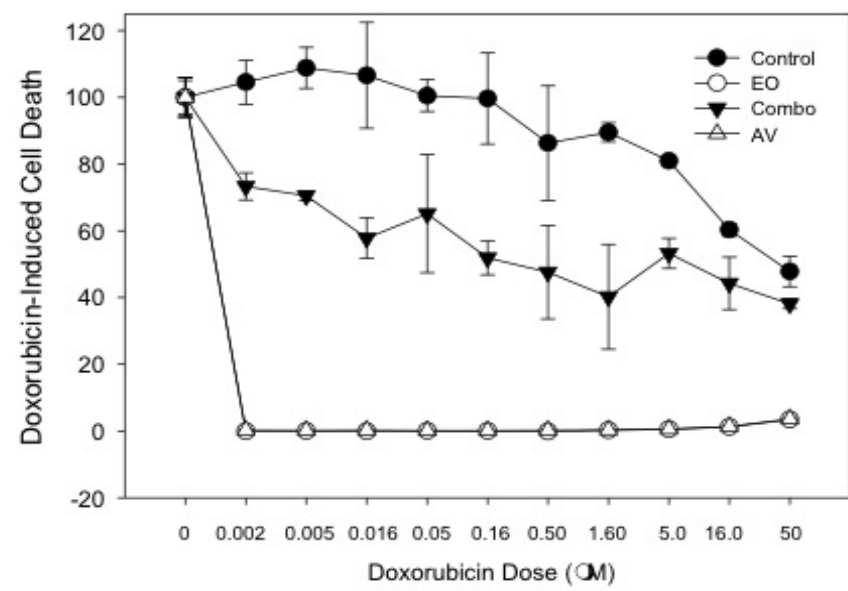

Figure 3: Pre-treatment with rinse agents did not protect against chemotherapeutic drug.Human fibroblasts were pre-treated with the essential oil-based product (EO, open circles), a combination product (combo, closed triangles) and an aloe vera-based rinse (AV, open triangles). All of the pretreatments caused more cell death than the doxorubicin alone (closed circles).

[36]. Unlike many previous studies, a water rinse control group was included in this research report. Oral bacterial levels trended lower with a single water rinse, but there were no statistically significant differences in the individual bacterial numbers before or after a water rinse. Rinsing with CHX also had little effect on the levels of individual types of bacteria. Only P. micros, a moderate-risk bacterium, was significantly reduced following a single rinse of $\mathrm{CHX}$. In fact that average percent change in each of the bacterium tested was a 3 percent reduction using CHX and a 2 percent increase with water. Neither was statistically different from the pre-treatment values. The lack of dramatic bacterial reduction with a CHX rinse is consistent with previous studies $[20,23]$. In fact, the strongest data supporting CHX as an antimicrobial agent are the in-vitro studies, while human clinical trials have failed to consistently demonstrate a positive effect [37]. In general, clinical trials have found no advantage of $\mathrm{CHX}$ treatment over conventional staged debridement [38]. For example, in a well-designed randomized, double-blind, placebo-controlled clinical trial, CHX treatment failed to reduce the microbiologic or clinical outcomes of reducing oral bacterial pathogens in mechanically-ventilated patients [39].

In contrast, 6 different bacteria were statistically reduced following a single rinse with the Combo product. Those included bacteria in the high-risk (A. actinomycetemcomitans and T. forsythia), moderaterisk, (F. nucleatum, P. intermedia, and P. micros) and low-risk categories (C species). A. actinomycetemcomitans was reduced by $39 \%$ after Combo treatment. A actinomycetemcomitans is an aggressive exogenous bacterium that invades periodontal tissues where it can destroy connective tissue and block the normal repair processes [40]. It is located in $90 \%$ of aggressive periodontitis, and $30-50 \%$ of severe periodontitis in adults [40]. T. forsythia, another high-risk bacteria found in the pockets of patients with periodontitis [41]. $T$ forsythia was reduced by $32 \%$ by the Combo treatment, but not by CHX. In the moderate-risk category $F$. nucleatum and $P$. intermedia were both reduced by the Combo treatment by 40 and 38\%, respectively. Both are associated with periodontal diseases [41]. They initially bind to organisms enhancing the adherence of other microbes to the oral cavity $[42,43]$. Therefore, they hold a central role in the onset 


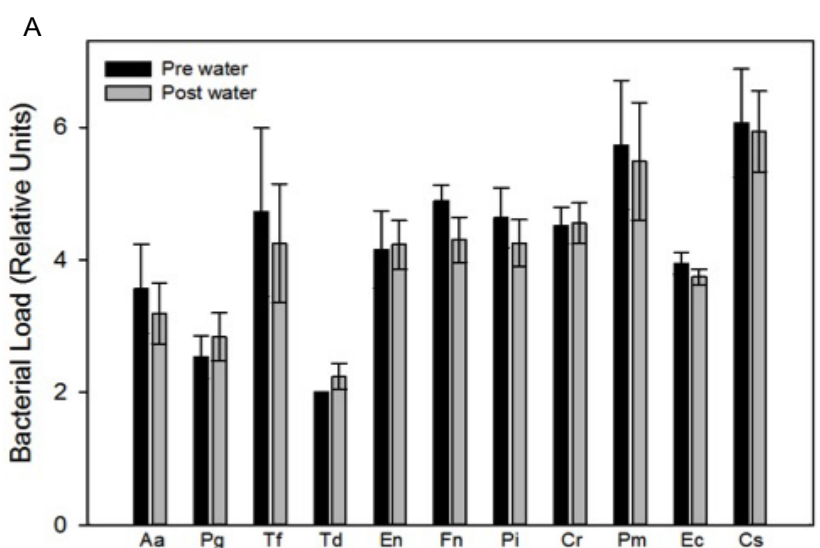

B

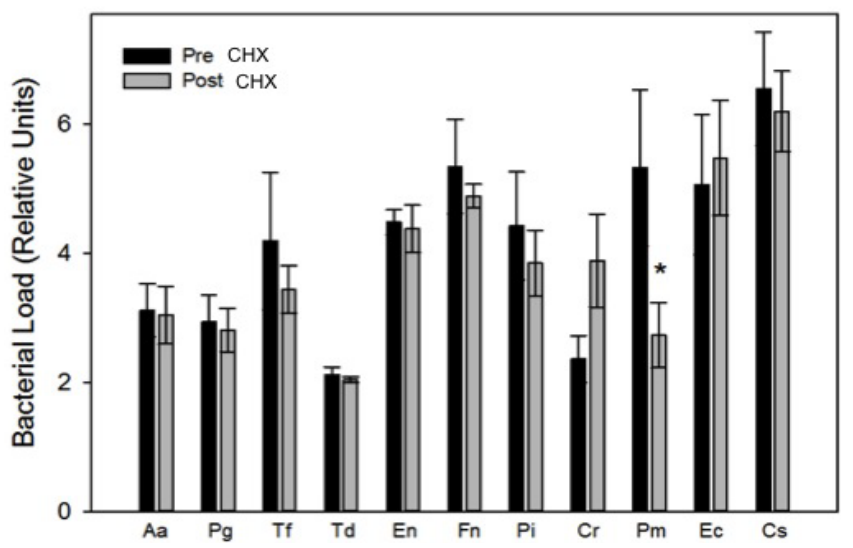

C

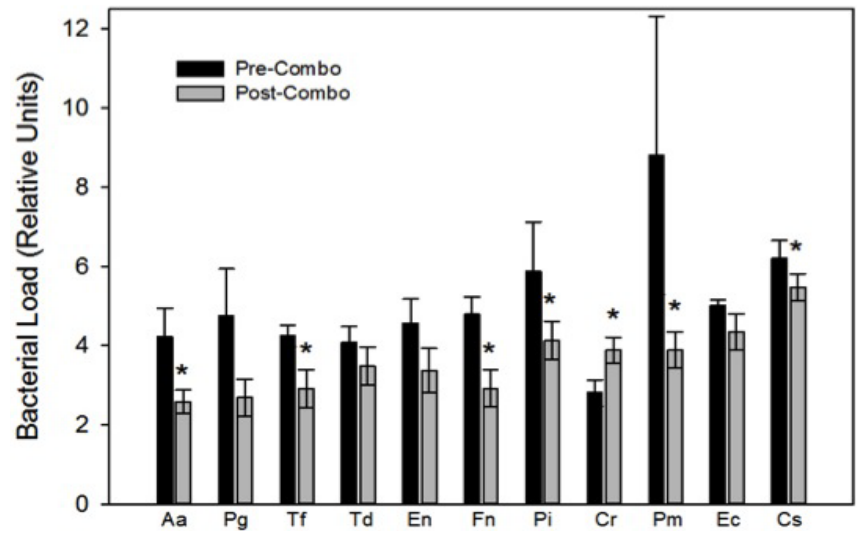

Figure 4: Bacterial DNA analyzed from sputum samples before and after treatment.A) Subjects provided a sputum sample for DNA analysis (pre water, black bars). They then rinsed with water and provided a second sample (post water, gray bars). There was no statistical difference within types of bacteria $(n=5)$. B) When the water rinse was replaced by $\mathrm{CHX}$, there was a statistically significant decrease in the Pm bacterium. ${ }^{*}$ indicated $p<0.05$ $(n=5)$. C) The same test was conducted using the combination rinse and statistically lower bacterial levels were measured in several of the bacterium. Cr showed a statistically significant increase in bacteria. $P<0.05(n=9)$. Aa: Aggregatibacter actinomycetemcomitans, Pg: Porphyromonas gingivalis , Tf: Tannerella forsythia, Td: Treponema denticola, En: Eubacterium nodatum, Fn: Fusobacterium nucleatum/periodonticum, Pi: Prevotella intermedia, Cr: Campylobacter rectus, Pm: Peptostreptococcus micros, EC: Eikenella corrodens, Cs: Capnocytophaga species. and subsequent development of polymicrobial periodontal diseases. Both types of bacteria can invade the oral cells, which can protect the bacteria from the host immune system [44]. P. micros bacterium, another moderate-risk category bacterium, was reduced by both $\mathrm{CHX}$ and Combo treatment. In general, it is considered more prevalent in gut microflora and involved in lower GI infections rather than oral disease. C. rectus is another moderate-level bacterium, but its levels actually increased in response to the Combo and CHX treatments. $C$. rectus is a poorly described gram-negative oral bacterium implicated with periodontitis, although attempts to associate $C$. rectus with the exact sites of periodontitis regions of the mouth have been conflicting $[45,46]$.

In the low risk category Capnocytophaga gingivalis was reduced by $12 \%$. While this bacterium is considered a lower risk for oral periodontal diseases, it has been strongly associated with oral squamous cell carcinoma [47], and therefore should not be considered harmless.

All products tested had negative effects on cell viability with the combination product containing $\mathrm{CP}$ and $\mathrm{EO}$ being the least toxic. These results were somewhat surprising, given that the exposure time was limited to only 30 seconds. The results highlight the acute negative impact that pure antimicrobial agents can have on healthy gingival cells. Most surprising was the toxic effect of the aloe verabased product, marketed as a healing and pain-reducing agent. The aloe vera-based agent was as toxic to gingival fibroblasts as the pure antimicrobial agents such as Listerine and CHX.

Finding the balance between bactericidal effects, without cellular toxicity is important for long-term home-based oral treatment. Many products will reduce oral bacteria loads [48], but may also cause additional health problems, especially in patients with comorbidities [49]. The combination product appeared optimal of the tested product. The exact ingredients in the products tested need to be further examined to identify the exact antimicrobial components versus those components inducing cellular toxicity.

\section{References}

1. Zarco MF, Vess TJ, Ginsburg GS (2012) The oral microbiome in health and disease and the potential impact on personalized dental medicine. Oral Dis 18: $109-120$.

2. Güngör ÖE, Kırzıoğlu Z, Dinçer E, Kıvanç M (2013) Who will win the race in childrens' oral cavities? Streptococcus mutans or beneficial lactic acid bacteria? Benef Microbes 4: 237-245.

3. Rajendhran J, Gunasekaran P (2010) Human microbiomics. Indian J Microbiol 50: 109-112.

4. Garcia RI, Henshaw MM, Krall EA (2001) Relationship between periodontal disease and systemic health. Periodontol 2000 25: 21-36.

5. Eke PI, Dye BA, Wei L, Thornton-Evans GO, Genco RJ; CDC Periodontal Disease Surveillance workgroup: James Beck (University of North Carolina, et al. (2012) Prevalence of periodontitis in adults in the United States: 2009 and 2010. J Dent Res 91: 914-920.

6. Tribble GD, Kerr J, Wang BY (2013) Genetic diversity of the oral pathogen Porphyromonas gingivalis: molecular mechanisms and biological consequences. Future Microbiol 8: 607-620.

7. Hajishengallis $G$ (2015) Periodontitis: from microbial immune subversion to systemic inflammation. Nat Rev Immunol 15: 30-44.

8. Ahn J, Segers S, Hayes R (2012) Periodontal disease, Porphyromonas gingivalis serum antibody levels and orodigestive cancer mortality. Carcinogenesis 33 : 1055-1058.

9. Michaud DS (2013) Role of bacterial infections in pancreatic cancer Carcinogenesis 34: 2193-2197.

10. Whitmore SE, Lamont RJ (2014) Oral bacteria and cancer. PLoS Pathog 10 e1003933. 
Citation: Bowen DJ, Cole C, McGlennen R (2015) Comparison of Antimicrobial and Wound Healing Agents on Oral Fibroblast Viability and In-vivo Bacterial Load. Dentistry 5: 305. doi:10.4172/2161-1122.1000305

11. Yao CS, Waterfield JD, Shen Y, Haapasalo M, Macentee MI (2013) In vitro antibacterial effect of carbamide peroxide on oral biofilm. J Oral Microbiol 5.

12. Al-Katma MK, Bissada NF, Bordeaux JM, Sue J, Askari AD (2007) Control of periodontal infection reduces the severity of active rheumatoid arthritis. J Clin Rheumatol 13: 134-137.

13. Nasr SH, Radhakrishnan J, D'Agati VD (2013) Bacterial infection-related glomerulonephritis in adults. Kidney Int 83: 792-803.

14. Chukkapalli S, Rivera-Kweh MF, Velsko IM, Chen H, Zheng D, Bhattacharyya I, et al. (2015) Chronic oral infection with major periodontal bacteria Tannerella forsythia modulates systemic atherosclerosis risk factors and inflammatory markers. Pathogens and disease. 73.

15. Louhelainen AM, Aho J, Tuomisto S, Aittoniemi J, Vuento R, et al. (2014) Ora bacterial DNA findings in pericardial fluid. J Oral Microbiol 6: 25835

16. Wahid A, Chaudhry S, Ehsan A, Butt S, Ali Khan A (2013) Bidirectional Relationship between Chronic Kidney Disease and Periodontal Disease. Pak J Med Sci 29: 211-215.

17. Noble JM, Scarmeas N, Papapanou PN (2013) Poor oral health as a chronic, potentially modifiable dementia risk factor: review of the literature. Curr Neurol Neurosci Rep 13: 384

18. Shangase SL, Mohangi GU, Hassam-Essa S, Wood NH (2013) The association between periodontitis and systemic health: an overview. SADJ 68: 8, 10-12.

19. Goldstep F (2013) Periodontal Inflammation: Simplified. Oral Health. 8-17.

20. Matesanz-Perez P, Garcia Gargallo M, Figuero E, Bascones Martinez A, Sanz $M$, et al. (2013) A systematic review on the effects of local antimicrobials as adjuncts to subgingival debridement, compared with subgingival debridement alone, in the treatment of chronic periodontitis. J Clin Periodontol 40: 227-241.

21. Cheung HY, Wong MM, Cheung SH, Liang LY, Lam YW, et al. (2012) Differential actions of chlorhexidine on the cell wall of Bacillus subtilis and Escherichia coli. PLoS One 7: e36659.

22. Teles RP, Teles FR (2009) Antimicrobial agents used in the control of periodontal biofilms: effective adjuncts to mechanical plaque control? Braz Oral Res 23 Suppl 1: 39-48.

23. Eberhard J, Jepsen, S, Jervoe-Storm PM, Needleman I, Worthington HV, et al (2008) Full-mouth disinfection for the treatment of adult chronic periodontitis. Cochrane Database Syst Rev. CD004622.

24. Lazarchik DA, Haywood VB (2010) Use of tray-applied 10 percent carbamide peroxide gels for improving oral health in patients with special-care needs. J Am Dent Assoc 141: 639-646.

25. Elfallah HM, Swain MV (2013) A review of the effect of vital teeth bleaching on the mechanical properties of tooth enamel. N Z Dent J 109: 87-96.

26. Pan P, Barnett ML, Coelho J, Brogdon C, Finnegan MB (2000) Determination of the in situ bactericidal activity of an essential oil mouthrinse using a vital stain method. J Clin Periodontol 27: 256-261.

27. Fine DH, Furgang D, Sinatra K, Charles C, McGuire A, et al. (2005) In vivo antimicrobial effectiveness of an essential oil-containing mouth rinse $12 \mathrm{~h}$ afte a single use and 14 days' use. J Clin Periodontol 32: 335-340.

28. Cosyn J, Princen KATRIJN, Miremadi R, Decat E, Vaneechoutte M, et al (2013) A double-blind randomized placebo-controlled study on the clinical and microbial effects of an essential oil mouth rinse used by patients in supportive periodontal care. Int J Dent Hyg. 11: 53-61.

29. Peterson DE, Bensadoun RJ, Roila F; ESMO Guidelines Working Group (2011) Management of oral and gastrointestinal mucositis: ESMO Clinical Practice Guidelines. Ann Oncol 22 Suppl 6: vi78-84.

30. Hans M, Madaan Hans V2 (2014) Epithelial antimicrobial peptides: guardian of the oral cavity. Int J Pept 2014: 370297.

31. McGuire DB, Fulton JS, Park J, Brown CG, Correa ME, et al. (2013) Systematic review of basic oral care for the management of oral mucositis in cancer patients. Support Care Cancer 21: 3165-3177.

32. Saunders DP, Epstein JB, Elad S, Allemano J, Bossi P, et al. (2013) Systematic review of antimicrobials, mucosal coating agents, anesthetics, and analgesics for the management of oral mucositis in cancer patients. Support Care Cance 21: $3191-3207$

33. Barber C, Powell R, Ellis A, Hewett J (2007) Comparing pain control and ability to eat and drink with standard therapy vs Gelclair: a preliminary, double centre, randomised controlled trial on patients with radiotherapy-induced oral mucositis. Supportive Care Cancer 15: 427-440.

34. Birsan I (2015) Polymerase chain reaction as a prospect for the early diagnosis and prediction of periodontal diseases in adolescents. Eur Arch Paediatr Dent 16: 9-12.

35. Parahitiyawa NB, Scully C, Leung WK, Yam WC, Jin LJ, et al. (2010) Exploring the oral bacterial flora: current status and future directions. Oral Dis 16: 136 145

36. Feng X, Zhu L, Xu L, Meng H, Zhang L, et al. (2015) Distribution of 8 periodontal microorganisms in family members of Chinese patients with aggressive periodontitis. Arch Oral Biol 60: 400-407.

37. Berezow AB, Darveau RP (2011) Microbial shift and periodontitis. Periodonto 2000 55: 36-47.

38. Lang N, Tan WC, Krahenmann MA, Zwahlen M (2008) A systematic review of the effects of full-mouth debridement with and without antiseptics in patients with chronic periodontitis. J. Clin Periodontol 35: 8-21.

39. Scannapieco FA, Yu J, Raghavendran K, Vacanti A, Owens SI, et al. (2009) A randomized trial of chlorhexidine gluconate on oral bacterial pathogens in mechanically ventilated patients. Crit Care 13: R117.

40. Raja M, Ummer F, Dhivakar CP (2014) Aggregatibacter actinomycetemcomitans - a tooth killer? J Clin Diagn Res 8: ZE13-16.

41. Tanner AC, Izard J (2006) Tannerella forsythia, a periodontal pathogen entering the genomic era. Periodontol 2000 42: 88-113.

42. Han YW, Shi W, Huang GTJ, Haake SK, Park NH, et al. (2000) Interactions between Periodontal Bacteria and Human Oral Epithelial Cells: Fusobacterium nucleatum Adheres to and Invades Epithelial Cells. Infect Immun 68: 31403148.

43. Santos S, Diniz CG, Silva VL, Martins WA, Cara DC, et al. (2007) Effects of oxidative stress on the virulence profile of Prevotella intermedia during experimental infection in gnotobiotic mice. J Med Microbiol 56: 289-297.

44. Tribble GD, Lamont RJ (2010) Bacterial invasion of epithelial cells and spreading in periodontal tissue. Periodontol 2000 52: 68-83.

45. Colombo AV, Silva CM, Haffajee A, Colombo AP (2006) Identification of ora bacteria associated with crevicular epithelial cells from chronic periodontitis lesions. J Med Microbiol 55: 609-615.

46. Dzink JL, Tanner AC, Haffajee AD, Socransky SS (1985) Gram negative species associated with active destructive periodontal lesions. J Clin Periodontol 12 648-659.

47. Mager DL, Haffajee AD, Devlin PM, Norris CM, Posner MR, et al. (2005) The salivary microbiota as a diagnostic indicator of oral cancer: a descriptive, nonrandomized study of cancer-free and oral squamous cell carcinoma subjects. J Transl Med 3: 27.

48. Tyski S, Bocian E, Mikucka A, Grzybowska W (2013) Antibacterial activity of selected commercial products for mouth washing and disinfection, assessed in accordance with PN-EN 1040. Med Sci Monit 19: 458-466.

49. Chevalier M, Sakarovitch C, Precheur I, Lamure J, Pouyssegur-Rougier V (2015) Antiseptic mouthwashes could worsen xerostomia in patients taking polypharmacy. Acta Odontol Scand 73: 267-273. 